\title{
A Magnitude Scale for Cascading Disasters
}

\section{David Alexander}

Institute for Risk and Disaster Reduction, University College London, Gower Street,

5 London WC1E 6BT, United Kingdom

E-mail address: david.alexander@ucl.ac.uk

\section{ABSTRACT}

This paper presents a magnitude scale for cascading incidents, crises and disasters.

The scale is listed, described and discussed in terms of its possible applications. A graphic form is presented as well as a tabular one. Examples are discussed in order to illustrate the different levels of the scale. The need for the scale is described in relation to evolving trends in research on cascading disasters, especially in terms of the cross-sector implications of critical infrastructure failure. By facilitating comparison between events, the scale may be able to help planners transfer knowledge and lessons from one cascading disaster to another, or to a situation in which one is likely. Future development of the scale might involve creating a quantitative means of applying it, connecting it to other scales designed to measure or assess disaster impacts and using it to understand the broader implications of infrastructure management decisions.

Keywords: Cascading disasters, Magnitude scale, Complexity, Emergency response, Crisis management, Disaster planning 


\section{Introduction}

As the $21^{\text {st }}$ century wears on, society is becoming increasingly complex and its components become ever more interdependent. Daily life and livelihoods now rely more than ever on technology, which has penetrated virtually every aspect of our lives. Moreover, people have high expectations of the functionality and reliability of the services on which they depend.

In modern life a complex dialectic relationship exists between human actions that reduce disaster risk, for example through prohibitions, built-in redundancies, damage limitation mechanisms and emergency plans, and those that increase it, for example, by building vulnerable structures in areas of high hazard. Vulnerability is being created as fast as it is being reduced, or perhaps faster. The 'wild card' in this relationship is public perception of risk, which is highly variable over time and which determines the level of demand for greater safety.

Given the central importance of critical infrastructure in modern life, attempts are being made to turn parts of it into high reliability systems that offer deep protection against failure or sabotage. Schulman et al. (2004) argued that complex, tightlycoupled systems can resist impacts by offering redundancy and close-knit resilience, whereas loosely-connected, decentralised systems offer targets for attack and impact. Whether or not this turned out to be true, critical infrastructure is often the channel by which cascading disasters propagate, and the extent of the cascade may reflect the degree to which safeguards have been built into both the system and the services, functions and clients who depend on it (Pescaroli and Kelman 2016).

The rise of complexity poses a challenge to the interpretation and understanding of disasters, and thus to their management. Disaster studies began about one hundred 
years ago with the assumption of a simple, direct relationship. A hazardous extreme 50 event acts upon human vulnerability to produce the negative consequences of disaster. To lessen the impact, people adapt to the hazard, insofar as it is known, by a form of 'human ecology' (Barrows 1923). Later work suggested that vulnerability is the key to the interpretation of disaster, and hazard is little more than the trigger. As hazard triggers vulnerability, the model, known as the 'radical critique', assumes that feedback loops exist between these two principal causes of disaster (Hewitt 1983).

Vulnerability is certainly at the heart of disaster. The concept has been interpreted in many different ways. For example, it has been analysed by geographical and personal scale (Wisner 1993), according to categories, such as physical, economic, social, environmental, and institutional (Birkmann et al. 2013), and in terms 60 of its relationship to poverty or wealth (Boyce 2000). The problem with a sectoral approach to vulnerability is that the sectors connect and interact in complex ways. Alexander (1997) sought to get around this by focussing on themes, such as delinquent vulnerability, the product of corruption or negligence, and technocratic vulnerability, the effect of excessive dependency on, or misuse of, technology. The essential and pervasive nature of vulnerability, and it centrality to the understanding of complex disasters, has long been noted (Timmerman 1981). As Pescaroli and Alexander (2015, p. 61) wrote: "...the relationship between vulnerability, politics, policies and crisis management capacities determines how escalating events are managed." However, only relatively recently has consideration been given to the idea that different vulnerabilities interact. As Birkmann (2006, p. 14) noted: "... social vulnerability is ... often determined by social networks in social, economic, political and environmental interactions." This puts the emphasis on interaction, but in terms of how 
the components or functions of society interact. A more specific understanding of how society's vulnerabilities interact is only now beginning to emerge (Pescaroli and Alexander 2016). McEntire (2001) explained the categories and made some progress towards setting up a framework for a more comprehensive analysis of vulnerability. One valuable concept is that of panarchy (Gunderson and Holling 2001), which allows for interaction between forces acting at different temporal and spatial scales, and across different sectors. As Gunderson and Holling (2001, p. 8) observed, "partial truths and bad decisions" result from failure to take interactions properly into account.

A further complication is provided by emerging risks, such as new forms of cyber-terrorism, disease mutations, and new consequences of technological failure (Aven 2016). Here, the knowledge of the event and its consequences is likely to be inferior to that of common and frequent hazards. In these instances, we know too little about the ways in which the impact will propagate and what its furthest consequences will be. Much of the knowledge we apply to cascading events has been acquired by experience, rather than calculation or prediction. Where experience is lacking, so is the ability to calculate and predict. Hence, a more sustained and rigorous approach to cascades may help us anticipate the poorly known aspects of emerging risks and their consequences.

In this paper I start from the premise that vulnerabilities in the modern world are largely not the product of single cause-effect relationships. Many vulnerabilities arise from mechanisms of connection between different factors. One way of looking at this is the "pressure and release" model of Blaikie et al. (2003, p 51), in which root causes, dynamic pressures and unsafe conditions come together and interact with extreme hazard events to create disasters. The underlying causes are the so-called 'risk 
drivers', many of which are connected with poverty, marginalisation and insecurity. Another way is explicitly to consider the risk drivers as agents of disaster risk creation (Burton 2015). Much more is needed to define the pattern of interactions between factors that cause disasters, and this represents a voyage of discovery that will be a major challenge for the present century. Disaster impacts cannot be reduced if they cannot be understood. Under present conditions, a good motto for seeking that understanding is to acknowledge that "one thing leads to another...".

The purpose of this paper is to present and describe a magnitude scale for cascading disasters. The rationale for such a scale is to facilitate the identification of cascades, so that they can be explored and investigated more fully, and their limits understood. As we live in a world of increasing complexity, it is highly probable that above a certain threshold of impact (and not a very high one), all disasters will be cascading events to a greater or lesser extent. Offering a structure for analysing them according to their magnitude may help clarify the planning and management needs associated with each size of event. The question to be answered is: "How far do we need to go in order to bring an adverse event under control and restore normality if such an event has cascading consequences?"

The rest of the paper is organised as follows. First, the cascading disasters are defined, and the concept is reviewed, in a manner designed to help understand the magnitude scale. Next, the scale is presented and described. A rationale for the scale and its application is offered, and its relationship with other scales used in disaster management is explored. Following on, the scale is illustrated with some examples of cascading disasters from the recent past. The next section briefly examines how the scale might contribute to the better management of cascading disaster events and the 
reduction of the risks associated with cascades in future disasters. The penultimate section considers the limitations of the scale and some directions for future work on the magnitude of disasters, not merely as damaging events, but also as damaging interactions between triggered vulnerabilities. Finally, the present work is summarised and concluding observations are made.

\section{Cascading disasters}

The definition of 'cascading disaster' was discussed in extenso in Pescaroli and Alexander (2015). Pescaroli and Alexander (2016) developed it further by comparing the phenomenon to other forms of compound disaster. An excerpt from the definition provided in Pescaroli and Alexander (2015, pp. 64-65) will form the working definition for this paper. It is as follows: "Cascading effects are the dynamics present in disasters, in which the impact of a physical event or the development of an initial technological or human failure generates a sequence of events in human subsystems that result in physical, social or economic disruption."

A phenomenon that makes cascading disasters particularly distinctive is the escalation point. This is a critical juncture in the chain of reactions to a disaster impact at which the interaction of vulnerabilities, and the concatenation of influences leads to a bigger impact than mere reaction to the primary disaster would suggest. The concept was discussed by Helbing (2012) and its implications for the management of critical infrastructure were explored by Van Eeten et al. (2011, pp. 390-391). It is far from inconceivable that an escalation point could be a greater source of disaster impact than was the initial event that set off the cascade. Hence, impacts do not necessarily fade and diminish as one proceeds down the cascade. They may well become more 
serious and complex. One of the most prominent examples of this is the triple disaster that struck northeast Japan in 2011. The magnitude 9 earthquake killed relatively few people, the tsunami that it provoked killed many more. It will be a long time before it is clear which was the worst disaster, the tsunami or the nuclear release from Fukushima Dai'ichi, with its problems of persistent radioactive contamination (Hindmarsh 2013). Cascading disasters were first studied in the context of critical infrastructure failures, both in the technical sphere (Rinaldi et al. 2001, Little 2002) and the social one (Boin and McConnell 2007, Galax et al 2011). They have also been considered in ecology as an outgrowth of studies of resilience in that field (Galaz et al. 2011), as well as in relation to propagation of negative impacts through the web of ecological 155 dependencies. Overall most cascading disasters research has been published within the last decade, with a notable increase in papers during the last five years. Some of the work covers the propagation of failures through networks, but this is largely restricted to individual categories of critical infrastructure (e.g. Wang and Rong 2011, Castillo 2014). Other research analyses the dependencies between networks (e.g. Cheng and Cao 2015). Yet more work deals with the implications for management (Boin and McConnell 2007) and resilience (Comes and Van de Walle 2014). Some research is methodological in character (Mignan et al. 2016) and some is specific to risk analysis (e.g. Gasparini and Garcia-Aristizabal 2014). Finally, a small number of papers look at cascading disasters purely in terms of the effect of one hazard upon another (e.g. Lin et al. 2008).

From this small but rapidly expanding body of literature, it is clear that cascading disasters involve questions of the reach or extent of the cascade and its taxonomy, or in other words how to characterise its properties. Those papers that analyse the cross- 
over effects of cascading disasters make it very clear that the taxonomic issue can be very complex indeed and its characterisation requires considerable ingenuity (Helbing 2013).

Consideration of the literature on cascading disasters suggests that it is time to adopt a more broadly taxonomic approach to them (cf. Mignan et al. 2016). The rationale is that a relationship can be traduced between small, simple cascades and large, complex ones. I contend that they can be classified by size, reach, complexity and importance, and in particular with respect to the causal relationships that they embody. Hence, the next section will offer a tentative scheme for such a classification.

\section{The cascading disasters magnitude scale}

Scales of magnitude and intensity are widely used in the study and management of natural hazards (e.g. Blong 2003). In their employment there is some ambiguity in the distinction between magnitude and intensity. For example, the difference is clear in seismic analysis, but less so in relation to tsunamis (Murty and Loomis 2009). Whereas damage is often described by intensity scales (e.g. Alexander 1988), and physical power by measures of magnitude (e.g. Kijko 2004), this is not always the case. In the present work, 'magnitude' is defined as size, geographical extent and richness of connections. It is also a measure of complexity, and, as impacts propagate in time, probably also of duration.

The justification for devising a magnitude scale for cascading disasters is not merely one of keeping up with the phenomena that have been similarly treated. The scale is an encouragement to seek out the limits of cascading impacts each time they occur. It is intended to encourage users to study the cross-sectoral effects and 
interactions between vulnerabilities that are root causes of cascades and escalations. Planning for emergencies and disasters is a process of exploring the possible contingencies that such events will generate and preparing for them, as far as possible, in advance in order to avoid unnecessary and inefficient improvisation (Alexander 2016). Planning for cascading disasters is particularly challenging because many of the disruptions, interactions and mobilisations of vulnerabilities are not immediately evident, as they depend on complex linkages (Sikula et al. 2015). Characterising the extent of such linkages is a vital process in understanding them and making contingency plans to deal with them.

The scale is intended to facilitate comparability between different events in terms of the extent to which they cascade. It is thus intended to help apply the lessons of one event to another by providing a basis for comparison that avoids problems of incompatible levels and different degrees of escalation. In devising the scale, there is no suggestion that all links, paths, nodes and exchanges can be foreseen, although many can. For emergency planners, failure to foresee the foreseeable could be construed as negligence, as it would lead to failure adequately to prepare. Pescaroli (2018) looked into this in the context of cascading disaster scenarios for London, UK, and found that failure to detect thresholds, or tipping points, would, in the event, probably lead to a series of negative consequences, including insufficient procurement of resources and inadequate response.

The cascading disasters and incidents magnitude scale is as follows. In this formulation, the following operational definitions are used. A crisis is "a threatening condition that requires urgent action" (UNISDR, 2009, p. 13). An incident is "a sudden event, usually resulting in an emergency, that requires a response from one or more 
agencies. Incidents are more restricted in scope and consequences than are disasters." (Alexander 2002, p. ). A disaster is "a serious disruption of the functioning of a community or a society involving widespread human, material, economic or environmental losses and impacts, which exceeds the ability of the affected community or society to cope using its own resources" (UNISDR, 2009, p. 9).

Table 1. The magnitude scale for cascading incidents, crises and disasters.

\section{A magnitude classification of cascading incidents, crises and disasters}

\section{Level 0 [Simple incident or major incident.]}

No evidence of significant cascades or escalation points. Simple, direct, linear causeand-effect relationships between the primary impact driver and its consequences. This level will mainly apply to geographically localised incidents of brief duration with no significant side-effects or knock-on consequences.

Level 1 [Major incident, of limited complexity.]

Evidence of simple, short cascades--i.e., secondary effects of the main or starting impact-effect relationship. There are no escalation points, no major interconnections or interactions beyond the early 'consequences of consequences' relationship. The most important relationship is that between the triggering event and its immediate consequences.

Level 2 [Major incident or small disaster, with some complex consequences.]

Limited cascade chains. The effects of the initial event propagate to tertiary levels in which there are significant complications or secondary emergencies at one remove or more from the triggering cause-effect event. The secondary emergencies may be as 
important or as pressing as the primary event. There may be escalation points, as new fields of vulnerability are penetrated by the extending chain of events.

Level 3 [Disaster, with complex consequences.]

Significant cascade chains can be detected, probably with at least one escalation point.

245 Different sectors of vulnerability are involved (physical, environmental, institutional, economic, social, etc.), and interaction occurs between them in an identifiable manner. There are complex interconnections between subsystems. As these both act upon different fields of vulnerability and connect them, compound consequences are detectable, some of which may have the power to escalate the general emergency.

Level 4 [Disaster, with substantially complex consequences.]

Cascades are easily identifiable in the effects of the disaster. Escalation points exist where particular vulnerability fields and states are encountered. Cascades substantially prolong the emergency and lead to effects that may outlast or overshadow the initial triggering event. The consequences of the disaster are complex on a wide variety of levels and they extend into many different aspects of daily life, which changes very significantly for the duration of the emergency and a substantial part of its aftermath.

Level 5 [Catastrophe, with overwhelmingly complex consequences.]

A major initial impact sets off long causal chains of cascading consequences, some of which, through identifiable escalation points, generate secondary causal chains. All of these extend into many or most aspects of normal daily life and cause very substantial disruption or total shut-down. Concurrent events occur or are triggered by compounding interconnections. The catastrophe disrupts and damages over a very 
wide scale and for a long time. Some effects are essentially global, for example on 265 intercontinental travel, international supply chains or global communications.

Figure 1 offers a graphic view of the scale. It is important to note that this is for illustrative purposes only. The actual disposition of nodes, linkages and pathways will depend on the circumstances of the incident, crisis or disaster. Nevertheless, the figure is designed to show the difference between the various levels of the scale.

Figure 1. A diagrammatic view of the cascading disasters magnitude scale.

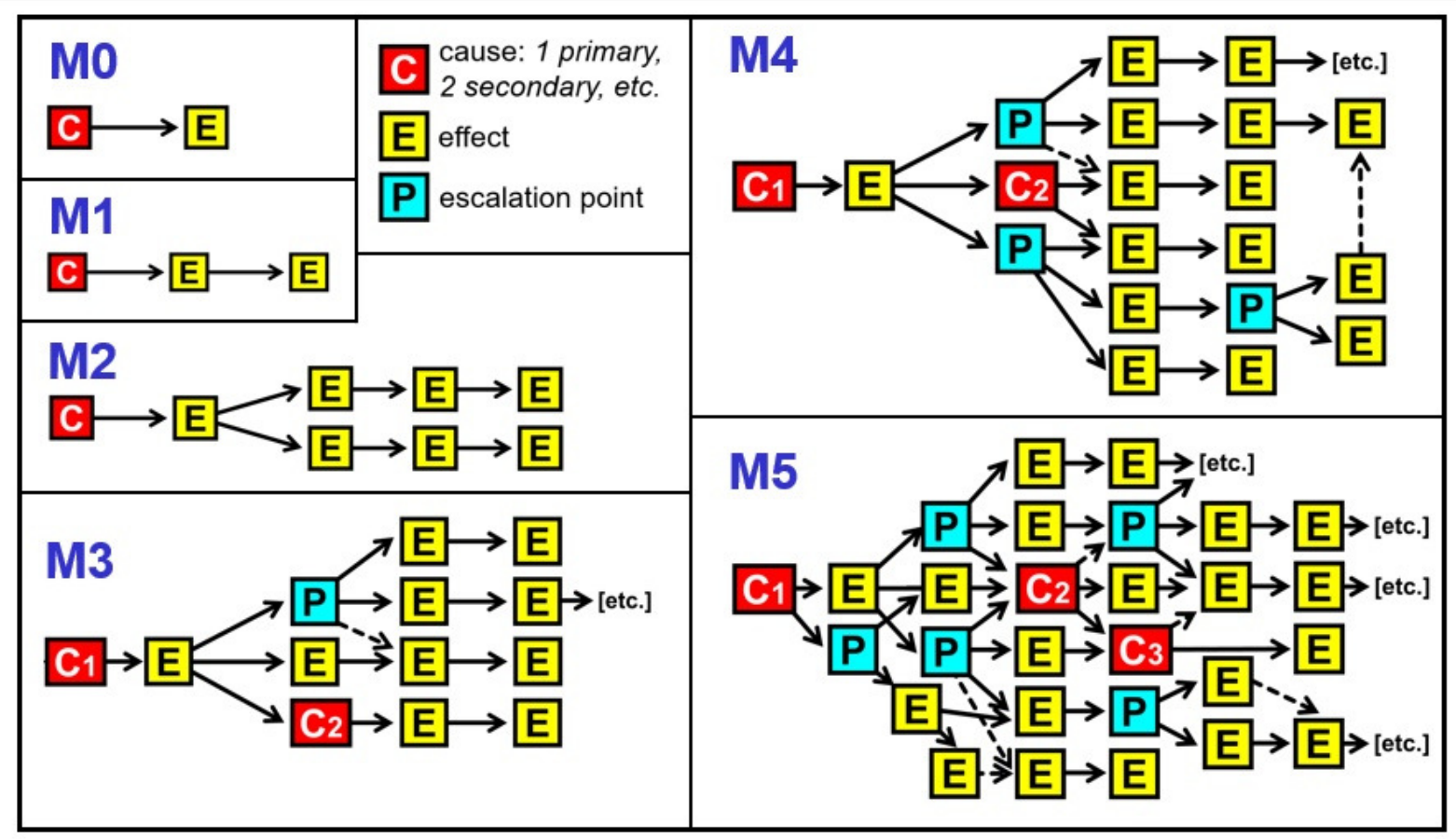

Some explanation is due in order to clarify the nature and wording of the scale. The distinctions between 'simple' and 'complex', and 'short' and 'long' are somewhat arbitrary and very dependent on expert judgement. So is the definition of 'significant'. 
These concepts depend on both expert judgement and their context. 'Short' might mean hours to days, and 'long' might mean days to weeks or months, but in many cases, it is the weight of consequences that determines whether a phenomenon seems short or long. Simplicity is in the eye of the beholder. As very little in cascading disasters may appear to be simple, it is clearly a term of great relativity.

When using the scale, one question of paramount importance is how to determine the level of a particular event. The scale is a model, and all models are simplifications of reality. Good models are elegant simplifications that selectively remove unhelpful detail ('noise') in order to emphasise explanatory material ('signal'). When following the chains of cause and effect inherent in a cascading disaster, users of the scale will need to make an expert judgement about where to stop. At a certain point there is little to be gained by prolonging the chain, and further linkages are not germane to an understanding of the event. This will help define the level on the scale to which an event corresponds.

In the present formulation, the scale is designed as a semantic tool which can be used to characterise cascading events. It is not a network tool. This begs the question whether such an instrument could be cast in quantitative terms. Looking for cascading effects could easily become a fractal process and needs to be kept within bounds. Nevertheless, this fact alone signifies that the relationship between levels in the scale is non-linear and possibly logarithmic. In reality, more research would be needed to operationalise the scale in mathematical terms. Inspiration could be gained 300 from fault and event trees, which are now routinely automated, modelled with algorithms and treated hierarchically (Kaiser et al. 2003). 
At a higher level of mathematical sophistication, multi-criteria decision analysis (MCDA) could be used to make the scale precise, objective and powerful. Since the late 1970s, multi-criteria decision analysis has developed as a sub-field of operations research (Stewart 1981). Building on the foundations of linear programming and other optimisation methods, it allows weights to be attributed to different decisions, for example, on the basis of the relative magnitude of different risks (Ganin et al. 2017). The present paper lays much emphasis on the use of scenarios to define the direction, magnitude and limits of cascades: with respect to elements of critical infrastructure, Karvetski et al. (2011) showed that multi-criteria decision analysis can be integrated with the scenarios in ways that help predict the most likely patterns of outcome. Thus, using MCDA, scenario analysis need no longer be an entirely quantitative methodology.

Cyber attacks involve networks and multiple criteria (obsolete or counterfeit hardware or software, ease of physical and logical access, financial and political gain, etc.). In this sense, not only are they potentially part of cascading events, but they are similar to such events in the sense that they propagate impacts (Ganin et al. 2017). Linkov et al. (2013a, p. 10109) produced a matrix model of physical, informational, cognitive and social resilience needs in policy development and then adapted it to cyber threats (Linkov et al. 2013b p. 474). In both cases, this provides a basis for classifying multiple decisions that can then be used to rank them with MCDA or similar methods. Quantification would allow the scale to be used predictively in the light of expressed preferences for particular decisions and outcomes, and expert judgement about what the likely consequences of particular impacts might be. 
In summary, the scale offers a taxonomic approach to cascading incidents, crises and disasters. Comparability is probably its best attribute, with concomitant ability to learn by comparing one incident with another in terms of its cascading attributes, especially the presence and significance of escalation points. As a final caveat emptor, as cascading disasters, crises and incidents are dynamic phenomena, their magnitude may change as they evolve, usually towards a higher level. Hence, the determination of level on the scale will usually be fully fixed only in backcasting scenarios, and not necessarily in real-time evaluations.

The next section will endeavour to explain the levels of the scale in terms of some practical examples that illustrate the relative degrees of complexity of cascading events.

\section{The scale in practice: some illustrations}

When using the scale, one of the most important challenges is how to determine the significance, level by level, of vulnerabilities, cause-effect relationships and consequences. In this analysis, a phenomenon or manifestation is significant (a) if it is a vital link in a cause-effect chain, (b) if it contributes significantly to the evolving picture and (c) if its absence from the model of the event would change the magnitude level.

Generally, using the scale requires the use of a scenario methodology (Alexander 2011, Renger et al. 2009). In the context of emergency planning and disaster reduction, a forward-looking scenario is not a prediction but an investigation of possible future outcomes derived from inputs selected on the basis of their importance to current trends. Backcasting scenarios are reconstructions of the main elements of past events, and their sequelae. In both cases, the scenario is a model, 
and when the technique is employed as a predictive model, it is appropriate to create a 'bundle' or 'envelope' of possible outcomes, as the input conditions may vary.

As always, the fundamental conceptual equation is the following, or some variant of it:-

$$
\text { Hazard } \rightarrow \text { Vulnerability [ / exposure ] } \rightarrow \text { Risk } \rightarrow \text { Impact }
$$

With cascades, it is likely to be considerably more complex, starting as follows:-

Hazard $\rightarrow$ Vulnerability $\mathrm{x}$ Vulnerability... [ / multiple exposures] $\rightarrow$ Extended impact

360 A more thorough investigation of the implications of cascades, relative to other sources of complexity in disaster, can be found in Pescaroli et al. (2018) and Pescaroli and Alexander (in press). The presence of these complexities is one reason why vulnerabilities come into play at different scales in time and space. This is one element that helps distinguish between different levels of the scale. Hence, the triggering of a vulnerability, or the interaction of vulnerabilities can increase the level on the scale of a cascading event. In this sense, magnitude does represent a step up in the intensity of interaction among the components of the cascade.

Direct cause and effect are represented by level 0 , in which a single impact leads to a single consequence, without significant cascades. Hence, a landslide that cuts a rural road in half or destroys a house might be such a case. Although there are consequences for the loss of the road or the house, they do not necessarily justify considering the event as a cascade. This underlines the importance of using 
judgement to determine whether it is worth characterising effects as part of a chain. In more sophisticated cases, this will probably require investigation of whether or not causal relationships exist.

On 18 January 2017 in the Province of L'Aquila, central Italy, four violent earthquakes occurred in the space of four hours. Three hours after the last shock and about $40 \mathrm{~km}$ from its epicentre, a snow avalanche triggered by the seismic activity destroyed a hotel, killing 29 of its 40 occupants. The rescue operations were particularly challenging because a blizzard had made roads to the hotel impassable. This probably represents level 1 in the scale, given the difficulties of saving lives in hostile conditions. Looked at on a broader scale, the Italian authorities had to deal simultaneously with massive snowfall that led to widespread, prolonged electricity blackout, earthquake damage, the crash of a relief helicopter with the loss of six lives and the avalanche. This would bring the event up to level 2 or beyond, thanks to the presence of concurrent impacts and the operational difficulties associated with all of them.

The 1971 San Fernando Valley (Sylmar) earthquake in California severely damaged two large hospitals. This complicated medical treatment (65 people were killed and 2,000 were injured), emergency medical response and emergency communication. Seismically-induced slumping on the rim of the Van Norman Dam led to an emergency for downstream residential areas that were at imminent risk of being inundated by a flood wave from the reservoir. These are escalation points that probably send this relatively moderate earthquake disaster (its magnitude was 6.6) to at least level 3 on the scale. 
It could be argued that Hurricane Katrina represents a level 4 cascade. Various escalation points can be noted, connected with failure to evacuate, the unsuitability of immediate shelter (the Superdome, which lost part of its roof), the physical failure of levees, and so on. Cascading consequences include questions of forced migration, 400 racism, and equity in the recovery process (Angel et al. 2012, Gemenne 2010). The April 2010 eruption of the Icelandic volcano Eyjafjallajökull is another candidate for level 4 cascade status. Not only were 8.5 million people stranded when civil aviation went into ground-stop over 70 per cent of Europe for almost a week, but commerce was severely affect and the short-term viability of some airlines was threatened (Alexander 2013).

Various candidates for level 5 exist. Perhaps the most prominent is the 'triple disaster' that struck northeast Japan on 11 March 2011, sometimes referred to as GEJET (the Great Eastern Japan Earthquake and Tsunami). The magnitude 9 earthquake that started this cascade killed no more than 100 people in the building collapses that it provoked, whereas 18,000 died in the tsunami. Major contamination, with risk of prolonged health effects, occurred as a result of the nuclear release from the Fukushima Dai'ichi plant. Industrial production was disrupted internationally as a result of the disaster, oceans were polluted with debris and radiation over a vast area, chemical hazards proliferated, infrastructure was destroyed on a vast scale, psychological problems were suffered by the survivors, and so it goes on (Hindmarsh 2013). The aftermath of GEJET provides a rich source of linkages for investigating cascades (e.g. Krausman and Cruz 2013).

Finally, the Indian Ocean tsunami of December 2004 is another candidate for level 5. Here, geographical scale is a factor, as the cascade would relate to the 
engagement of international systems, including the UN-coordinated humanitarian relief (Telford and Cosgrave 2007) and the consequences for 11 or 12 countries that were directly affected and countries, such as Sweden and the United Kingdom, that saw significant numbers of their citizens killed and injured (Olofsson 2011).

Especially with respect to the higher levels of the scale, a proper evaluation is 425 needed in order to determine where a particular disaster should be placed. Hence, the present examples are purely for illustration.

A brief justification will now be given concerning the possible value of the scale in practical terms. Classification is seldom an end in itself. but instead it needs to be put to use in the service of other objectives. When an incident occurs or disaster strikes, or where such things are expected, I hope that the magnitude scale may help emergency planners and managers to explore and appreciate the scale and extent of possible cascades. The scale may also help to promote understanding of the implications of technical decisions in infrastructure management. Very often, these decisions have social, economic, political and psychological repercussions that need to be taken into account. I trust that the scale will be useful as a means of thinking about how far cascades extend in terms of the lengths of chains of cause and effect. That may, not only focus attention in the cascade chains and their nodes and escalation points, but also give a more realistic idea of where the impact of disaster stops. At present, I suspect that much of the impact of big events is effectively hidden. I will now offer a few ideas on the place of this work in current research and possible future directions suggested by current needs. The paper will end with a summary conclusion. 


\section{Implications and future directions}

As noted at the start of this paper, it is likely that all disasters with a modicum of complexity will be cascading events to a greater or lesser degree. This reflects the increasing complexity and interdependency of society, and the processes of globalisation that have affected many different aspects of modern life (Helbing 2013). In the interests of short-term efficiency, supply chains are tighter, or 'leaner' than they were in the past, but they are also more extensive over geographical space. These characteristics leave them vulnerable to major disruption. Both contingencies that occur and decisions that are taken in one part of the world can have immediate consequences in another. As a result of these and many other factors, failure to take cascading effects into account can lead planners and managers to ignore key eventualities and have misplaced priorities.

In disaster research, the study of cascades is a young endeavour but one that is growing fast. At the present time the frontier lies, not so much in understanding and dealing with cascading effects in a single sector, such as electricity distribution or the transportation of relief goods, but in the mutual effects of failure in one field upon that in another. There are nine categories of critical infrastructure (Cabinet Office 2010, p. 24), and they all interact, not only with normal, daily life (that is what makes them 'critical') but with each other. Understanding the interactions is a major challenge. For instance, prolonged, wide-area power failures have many cascading impacts on people, activities and processes that depend on the supply of electricity (Pescaroli et al. 2017). Redundancy that either keeps the supply going or finds alternative solutions to the use of electricity is limited. Hence, electricity supply is now firmly "part of the 
culture", but, other than in a purely technical sense (Novosel et al. 2004), relatively little is known about the implications of doing without it, especially in large cities.

In the majority of cases, failure of critical infrastructure is the driver of cascading disaster. We now need to expand our work from studying how that failure occurs to what its consequences are, and not merely the primary ones. In 2002, flooding in the Czech Republic caused an explosion and a toxic cloud at a chemical factory in Spolana (Krausmann and Mushtaq 2008). Fifteen years later, at the end of August 2017, flooding caused by Hurricane Harvey led to an exactly analogous event in a chemical plant at Crosby, Texas (Smulison 2017). The challenge is to anticipate such events by better planning, which may involve classification as a means of appreciating the links between events and their relative importance. Krausmann and Mushtaq (2008, pp. 184-186) offered a classification of industrial accidents. There may be scope for connecting up this and similar initiatives with the cascading disasters magnitude scale.

\section{Conclusion}

This paper offers a preliminary version of a magnitude scale for cascading incidents, crises and disasters. The approach taken is a taxonomic, semantic one, which describes a set of levels corresponding to progressively more complex articulations of the scale. As the current initiative is not a quantitative one, application of the scale requires some expert judgement about where cascades begin and end, how they are configured and what is the significance of each trigger, node, pathway and escalation point. Future work may involve applying decision science to the scale, especially multi-criteria decision analysis, in order to render it more precise and 
used in contexts in which the determination of level and effects is preliminary pending changes in the field situation or the arrival of new data. Nevertheless, the scale offers a basis for categorising events as cascades, focussing on the chains of cascade and their limits, comparing different events in cascading terms, and discovering contingencies that need to be planned for in advance of the next disaster.

\section{Acknowledgements}

This paper stems from work carried out under the aegis of the European Commission's FORTRESS project (grant no. 607579); FP7 Area 10.4.1 Preparedness,

Prevention, Mitigation and Planning, TOPIC SEC-2013.4.1-2 SEC-2013.2.1-2. The work was also supported by a Knowledge Exchange Grant from University College London. I thank Dr Robert Wicks for his wise and insightful comments on the magnitude scale.

\section{References}

Alexander, D.E., 1988. Developing a landslide damage scale: the lessons of the Great Ancona Landslide of 1982. Ground Failure 4: 1, 9-11.

Alexander, D.E. 1997. The study of natural disasters, 1977-97: some reflections on a changing field of knowledge. Disasters 21(4): 284-305.

510 Alexander, D.E. 2002. Principles of Emergency Planning and Management. Terra, Harpenden, UK, and Oxford University Press, New York, 340 pp.

Alexander, D.E. 2011. Building scenarios. In C. Vinchon, M-L. Carreño, D.M. Contreras-Mojica et al. Assessing Vulnerability to Natural Hazards in Europe: 
From Principles to Practice. A Manual on Concept, Methodology and Tools (The MOVE Manual). BGRM, Paris: 40-41.

Alexander, D.E. 2013. Volcanic ash in the atmosphere and risks for civil aviation: a study in European crisis management. International Journal of Disaster Risk Science 4(1): 9-19.

Alexander, D.E. 2016. How to Write an Emergency Plan. Dunedin Academic press, Edinburgh and London, $268 \mathrm{pp}$.

Angel, R.L., H. Bell, J. Beausoleil and L. Lein 2012. Community Lost: The State, Civil Society, and Displaced Survivors of Hurricane Katrina. Cambridge University Press, New York, 241 pp.

Aven, T. 2016. Risk assessment and risk management: review of recent advances on their foundation. European Journal of Operational Research 253(1): 1-13.

Barrows, H.H. 1923. Geography as human ecology. Annals of the Association of American Geographers 13: 1-14.

Birkmann, J. 2006. Measuring vulnerability to promote disaster-resilient societies: conceptual frameworks and definitions. In J. Birkmann (ed.) Measuring Vulnerability to Natural Hazards: Towards Disaster Resilient Societies. United Nations University Press, Tokyo: 9-54.

Birkmann, J., O.D. Cardona, M.L. Carreño, A.H. Barbat, M. Pelling et al. 2013. Framing vulnerability, risk and societal responses: the MOVE framework. Natural Hazards 67(2): 193-211.

535 Blaikie, P., T. Cannon, I. Davis and B. Wisner 2003. At Risk: Natural Hazards, People's Vulnerability and Disasters (2nd edition). Routledge, London.

Blong, R. 2003. A review of damage intensity scales. Natural Hazards 29(1): 57-76. 
Boin, A. and A. McConnell 2007. Preparing for critical infrastructure breakdowns: the limits of crisis management and the need for resilience. Journal of Contingencies and Crisis Management 15(1): 50-59.

Boyce, J.K. 2000. Let them eat risk: wealth, rights and disaster vulnerability. Disasters 24(3): 254-261.

Burton, I. 2015. The forensic investigation of root causes and the post-2015 framework for disaster risk reduction. International Journal of Disaster Risk Reduction 12: 12.

Cabinet Office 2010. Strategic Framework and Policy Statement on Improving the Resilience of Critical Infrastructure to Disruption from Natural Hazards. United Kingdom Cabinet Office, London, 26 pp.

Castillo, A. 2014. Risk analysis and management in power outage and restoration: a literature survey. Electric Power Systems Research 107: 9-15.

Cheng, Z. and J. Cao 2015. Cascade of failures in interdependent networks coupled by different type networks. Physica A: Statistical Mechanics and its Applications 430: 193-200.

Comes, T. and B. Van de Walle 2014. Measuring disaster resilience: the impact of Hurricane Sandy on critical infrastructure systems. In S.R. Hiltz, M.S. Pfaff, L. Plotnick and P.C. Shih (eds) Proceedings of the 11th International ISCRAM Conference, University Park, Pennsylvania, USA, May 2014: 195-204.

Galaz, V., F. Moberg, E-K. Olsson, E. Paglia and C. Parker 2011. Institutional and political leadership dimensions of cascading ecological crises. Public Administration 9(2): 361-380. 
Ganin, A.A., P. Quach, M. Panwar, Z.A. Collier, J.M. Keisler, D. Marchese and I. Linkov 2017. Multicriteria decision framework for cybersecurity risk assessment and management. Risk Analysis DOI: 10.1111/risa.12891

Gasparini, P. and A. Garcia-Aristizabal 2014. Seismic risk assessment, cascading effects. In M. Beer, I.A. Kougioumtzoglou, E. Patelli and I.S-K. Au (eds) Encyclopedia of Earthquake Engineering. Springer, Berlin: 1-20.

Gemenne, F. 2010. What's in a name: social vulnerabilities and the refugee controversy in the wake of Hurricane Katrina. In T. Afifi and J. Jäger (eds) Environment, Forced Migration and Social Vulnerability. Springer, Berlin: 29-40.

570 Gunderson, L.H. and C.S. Holling (eds) 2001. Panarchy: Understanding Transformations. In Human and Natural Systems. Island Press, Washington, DC., $507 \mathrm{pp}$.

Helbing, D. 2012. Systemic risks in society and economics. In D. Helbing (ed.) Social Self-Organization: Agent-Based Simulations and Experiments to Study Emergent Social Behaviour. Springer, Berlin: 261-284.

Helbing, D. 2013. Globally networked risks and how to respond. Nature 497: 51-59.

Hewitt, K. 1983. The idea of calamity in a technocratic age. In K. Hewitt (ed.) Interpretations of Calamity from the Viewpoint of Human Ecology. Unwin-Hyman, London: 3-32.

Hindmarsh, R. 2013. Nuclear Disaster at Fukushima Dai'ichi: Social, Political and Environmental Issues. Routledge, London, 222 pp.

Kaiser, B., P. Liggesmeyer and O. Mäckel 2003. A new component concept for fault trees. Eighth Australian Workshop on Safety Critical Systems and Software, Canberra: 1-10. 
585 Karvetski, C.W., J.H. Lambert, and I. Linkov 2011. Scenario and multiple criteria decision analysis for energy and environmental security of military and industrial installations. Integrated Environmental Assessment and Management 7(2): 228-236.

Kijko, A. 2005. Estimation of the maximum earthquake magnitude, m max. Pure and Applied Geophysics 161: 1-27.

Krausmann, E. and A.M. Cruz 2013. Impact of the 11 March 2011, Great East Japan earthquake and tsunami on the chemical industry. Natural Hazards 67(2): 811828.

Krausmann, E. and F. Mushtaq 2008. A qualitative Natech damage scale for the impact of floods on selected industrial facilities. Natural Hazards 46(2): 179-197.

Lin, W-T., C-Y. Lin, J-S. Tsai and P-H. Huang 2008. Eco-environmental changes assessment at the Chiufenershan landslide area caused by catastrophic earthquake in Central Taiwan. Ecological Engineering 33(3-4): 220-232.

Linkov, I., D. Eisenberg, M. Bates, D. Chang, M. Convertino, J. Allen, S. Flynn and T. 600 Seager 2013a. Measurable resilience for actionable policy. Environmental Science and Technology 47: 10108-10110.

Linkov, I., D.A. Eisenberg, K. Plourde, T.P. Seager, J. Allen and A. Kott 2013 b. Resilience metrics for cyber systems. Environment Systems and Decisions 33(4): 471-476.

605 Little, R.G. 2002. Controlling cascading failure: understanding the vulnerabilities of interconnected infrastructures. Journal of Urban Technology 9(1): 109-123.

McEntire, D.A. 2001. Triggering agents, vulnerabilities and disaster reduction: towards a holistic paradigm. Disaster Prevention and Management 10(3): 189-196. 
Mignan, A., A. Scolobig and A. Sauron 2016. Using reasoned imagination to learn about cascading hazards: a pilot study. Disaster Prevention and Management 25(3): 329-344.

Murty, T.S. and H.G. Loomis 2009. A new objective tsunami magnitude scale. Marine Geodesy 4(3): 267-282.

Novosel, D., M.M. Begovic and V. Madani 2004. Shedding light on blackouts. IEEE Power and Energy Magazine January-February 2004: 32-43.

Olofsson, A. 2011. The Indian Ocean tsunami in Swedish newspapers: nationalism after catastrophe. Disaster Prevention and Management 20(5): 557-569.

Pescaroli, G. 2018. Perceptions of cascading risk and interconnected failures in emergency planning: implications for operational resilience and policy making. International Journal of Disaster Risk Reduction.

https://doi.org/10.1016/j.ijdrr.2018.01.019

Pescaroli, G. and D. Alexander 2015. A definition of cascading disasters and cascading effects: going beyond the "toppling dominos" metaphor. Planet@Risk 3(1): 58-67.

625 Pescaroli, G. and D. Alexander 2016. Critical infrastructure, panarchies and the vulnerability paths of cascading disasters. Natural Hazards 82(1): 175-192.

Pescaroli, G. and D. Alexander, in press. Understanding compound, interconnected, interacting and cascading risks: a holistic framework. (forthcoming).

Pescaroli, G. and I. Kelman 2016. How critical infrastructure orientates international relief in cascading disasters. Journal of Contingencies and Crisis Management 25(2): 56-67. 
Pescaroli, G., S. Turner, T. Gould, D.E. Alexander and R.T. Wicks 2017. Cascading Effects and Escalations in Wide Area Power Failures: A Summary for Emergency Planners. Cascading Disasters Research Group, Institute for Risk and Disaster Reduction, University College London, London, 15 pp.

Pescaroli, G., R.T. Wicks, G. Giacomello and D.E. Alexander 2018. Increasing resilience to cascading events: the M.OR.D.OR. scenario. Safety Science doi.org/10.1016/j.ssci.2017.12.012

Renger, R., J. Wakelee, J. Bradshaw and L. Hites 2009. Steps in writing an effective master scenario events list. Journal of Emergency Management 7(2): 51-60.

Rinaldi, S.M., J.P. Peerenboom and T.K. Kelly 2001. Identifying, understanding, and analyzing critical infrastructure interdependencies. IEEE Control Systems Magazine December 2001: 11-25.

Schulman, P., E. Roe, M.V. Eeten, and M.D. Bruijne 2004. High reliability and the management of critical infrastructures. Journal of Contingencies and Crisis Management 12(1): 14-28.

Sikula, N.R., J.W. Mancillas, I. Linkov and J.A. McDonagh 2015. Risk management is not enough: a conceptual model for resilience and adaptation-based vulnerability assessments. Environmental Systems and Decisions 35: 219-228.

650 Smulison, J. 2017. Post-Harvey lessons for industrial facilities. Risk Management 64(9): 4-7.

Stewart, T.J. 1981. A descriptive approach to multiple-criteria decision making. Journal of the Operational Research Society 32(1): 45-53.

Telford, J. and J. Cosgrave 2007. The international humanitarian system and the 2004 Indian Ocean earthquake and tsunamis. Disasters 31(1): 1-28. 
Timmerman, P. 1981. Vulnerability, Resilience and the Collapse of Society. Environmental Monograph no. 1, Institute for Environmental Studies, University of Toronto, Toronto, $42 \mathrm{pp}$.

UNISDR 2009. Terminology on Disaster Risk Reduction. United Nations International Strategy for Disaster Reduction, Geneva, $30 \mathrm{pp}$.

Van Eeten, M., A. Nieuwenhuijs, E Luiijf, M. Klaver and E. Cruz 2011. The state and the threat of cascading failure across critical infrastructures: the implications of empirical evidence from media incident reports. Public Administration 89(2): 381 400.

665 Wang, J-W. and L-L. Rong 2011. Robustness of the western United States power grid under edge attack strategies due to cascading failures. Safety Science 49: 807812.

Wisner, B. 1993. Disaster vulnerability: scale, power and daily life. GeoJournal 30(2): 127-140. 